\title{
UMA HISTÓRIA DO PROCESSO DE ENFERMAGEM NAS PUBLICAÇÕES DA REVISTA BRASILEIRA DE ENFERMAGEM NO PERIODO 1960-1986a
}

\author{
A History of the nursing process in Brazilian Nursing Magazine's \\ publications in the period of 1960-1986 \\ Una Historia del proceso de enfermería en las publicaciones \\ de la Revista Brasileña de Enfermería en el periodo 1960-1986
}

Denise Faucz Kletemberg

Márcia Dalledone Siqueira

Maria de Fátima Mantovani

\begin{abstract}
Resumo
Estudo de natureza histórica cujo objetivo é analisar a implementação do processo de enfermagem no Brasil, no período de 1960 a 1986. As fontes históricas compõem-se de 47 artigos selecionados na Revista Brasileira de Enfermagem, no período referido, que apresentam reflexões sobre a prática assistencial da época, relatos de experiências da aplicação do Processo de Enfermagem e os artigos de autoria de Wanda de Aguiar Horta. Os achados da análise dos artigos, contextualizados com aspectos político-econômicos apontam as causas das dificuldades encontradas pela categoria para implementação da metodologia da assistência de enfermagem, diante das exigências antagônicas do mercado de trabalho no período analisado. Portanto, as dificuldades e resistências experienciadas não couberam apenas à vontade dos profissionais, mas, sim, permearam-se pelos interesses antagônicos da sociedade brasileira.
\end{abstract}

Palavras-chave: Processos de Enfermagem. História da Enfermagem. Metodologia. Diagnóstico de Enfermagem. Cuidados de Enfermagem.

\begin{abstract}
This is by nature a historical research, which intends to analyze the implementation of Nursing Process (Nursing Assistance Methodology) in Brazil, in the period of 1960 to 1986 . The historical sources are 47 articles selected among the ones published by Revista Brasileira de Enfermagem (Brazilian Magazine on Nursing), in that period. The article selection criteria were that they had to deal somehow with reflections on nursing assistance practice, or to be experience reports on nursing process implementation, also Wanda de Aguiar Horta's articles were selected. The findings of the articles analysis, contextualized with public politician-economic aspects, indicated what caused the difficulties for the implementation of such methodology, ahead of the antagonistic requirements of the market of work in the analyzed period. Therefore, the tried difficulties and opposition not fit only to the will of the professionals, but, yes, they had been larded for the antagonistic interests of the Brazilian society.
\end{abstract}

\section{Resumen}

Estudio de naturaleza histórica cuyo objetivo es analizar la implementación de la Metodología de la Asistencia de Enfermería en el Brasil, en el período de 1960 a 1986. Las fuentes históricas se componen de 47 artículos seleccionados en la Revista Brasileña de Enfermería, en el período referido, que presentan reflexiones sobre la práctica asistencial de la época., relatos de experiencias de la aplicación del Proceso de Enfermería y los artículos de autoría de Wanda de Aguiar Horta. Los resultados del análisis de los artículos, contextualizados con aspectos políticoeconómicos, apuntan las causas de las dificultades encontradas por la categoría para implementación de la metodología de la asistencia de enfermería, delante de los requisitos antagónicos del mercado del trabajo en el período analizado. Por lo tanto, las dificultades y las oposiciones probadas no habían cabido solamente a la voluntad de los profesionales, pero, sí, habían sido intercambiados por los intereses antagónicos de la sociedad brasileña.
Keywords: Nursing Process. Nursing History. Methodology. Nursing Diagnosis. Nursing Care.
Palabras clave: Procesos de Enfermería. Historia de la Enfermería. Metodología. Diagnóstico de Enfermería. Atención de Enfermería. 


\section{INTRODUÇÃO}

No Brasil, o emprego do processo de enfermagem foi incentivado por Wanda de Aguiar Horta, na década de 1970, em São Paulo, que trouxe como referencial teórico a Teoria das Necessidades Humanas Básicas de Maslow.. Assim, a assistência de enfermagem deveria se embasar em uma metodologia científica, que privilegiasse cinco etapas: levantamento de dados (histórico), diagnóstico, planejamento, execução e avaliação.

A nomenclatura da aplicação do método científico na prática da enfermagem* tem sofrido variações de acordo com a época histórica e o referencial teórico adotado. Assim:

A diversidade de paradigmas que permeiam o diaa-dia da Enfermagem aponta diversas nomenclaturas para designar a Metodologia da Assistência de Enfermagem, [...] Entre elas, podemos citar: Processo de Enfermagem, Processo de Cuidado, Metodologia do Cuidado, Processo de Assistir, Consulta de Enfermagem ${ }^{1: 18 .}$.

Entretanto, o enfermeiro tem encontrado dificuldades na aplicação da metodologia da assistência de enfermagem como instrumento científico de trabalho, devido a obstáculos internos e externos à enfermagem, dentre os quais estão as estruturas institucionais, o processo de trabalho deste profissional, a lógica da priorização da atenção médica individualizada e curativa, além da forma como ocorre sua aprendizagem na graduação. Esta nossa percepção está fundamentada em pesquisas, como de $\mathrm{Meier}^{2}$; Mendes e Bastos ${ }^{3}$; Thofehrn et al ${ }^{4}$, quando relatam a ausência ou a implantação parcial do processo de enfermagem, bem como as dificuldades encontradas pelos enfermeiros. Frente ao fato exposto, questionase como ocorreu a implementação do processo de enfermagem no Brasil? Este resgate se faz necessário para compreensão dos constituintes históricos que acarretaram as dificuldades encontradas ainda hoje para a aplicação do método científico na prática assistencial.

Assim, este trabalho fez uma análise histórica da implementação da metodologia da assistência de enfermagem no Brasil contextualizando seu desenvolvimento em relação aos determinantes socioeconômicos e políticos que direcionavam as políticas de saúde brasileiras, nas décadas de 60 a 80 . 0 período demarcado atende à época de início da implementação da sistematização da assistência na literatura de enfermagem e a publicação da Lei 7.498, de 25 de junho de $1986^{5}$, que dispõe sobre o exercício profissional da enfermagem introduzindo como atividade privativa do enfermeiro, a elaboração, execução e avaliação dos planos assistenciais de saúde.

A relevância da aplicação da metodologia científica para a valorização profissional ficou impressa na categoria, desde sua implantação, registradas nas publicações da Revista Brasileira de Enfermagem, neste período.

\section{METODOLOGIA}

Trata de uma pesquisa qualitativa com utilização do método histórico, pois a história não é a busca de um tempo homogêneo e vazio, preenchido pelo historiador com a sua visão dos acontecimentos, ela é muito mais uma busca de respostas para os 'agoras'.

0 presente artigo traz uma abordagem histórica sobre o processo de enfermagem e de como ele é veiculado na Revista Brasileira de Enfermagem (REBEn). Embora haja diversidade de termos na atualidade para aplicação do método científico na prática assistencial da enfermagem será adotada a forma como ele aparece nas fontes da época estudada, ou seja, Processo de enfermagem.

Assim, para este estudo, arrolaram-se como fontes históricas artigos publicados na REBEn, entre 1960 e 1986, da qual foram pesquisados 27 volumes, contendo 108 números do periódico, o que resultou em 47 artigos sobre o tema.

0 critério de escolha da REBEn foi o seu alcance geográfico e ser essa publicação de responsabilidade da Associação Brasileira de Enfermagem (ABEn), refletindo, portanto, o pensamento e a prática assistencial do enfermeiro. A importância da revista, nos meados do século $X X$, foi referendada na literatura de enfermagem à época ao enfatizar que esta era o único veículo de comunicação dos profissionais de enfermagem, com circulação em todo território nacional ${ }^{7: 64}$.

A seleção dos artigos constou de análise de seus título e resumo; se eles eram indicativos de reflexões sobre a prática assistencial da época. Os artigos incluíram ainda relatos de experiências da aplicação do processo de enfermagem e os artigos de autoria de Wanda de Aguiar Horta.

\section{O PROCESSO DE ENFERMAGEM}

0 primeiro artigo publicado na Revista Brasileira de Enfermagem sobre sistematização da assistência de enfermagem, no período proposto, é de autoria de Wanda de Aguiar Horta, intitulado Considerações sobre o diagnóstico de Enfermagem, de $1967^{8}$. Esse fato confirma a autora como precursora da aplicação da metodologia científica no Brasil e a forte influência dela 
durante as décadas seguintes. Para ela diagnosticar era uma forma de aplicar o método científico utilizandoo na busca da verdade ou na sua exposição.

Horta define neste artigo que, diagnosticar é, em síntese, aplicar o método científico, isto é, a utilização dos processos lógicos pelo pensamento, na busca da verdade ou na sua exposição. Os processos gerais de pensamento são utilizados de modo sistemático e refletido na procura do diagnóstico ${ }^{8}$.

Eis a nova idéia que Wanda Horta trazia: sistematizar o pensamento, o raciocínio, para levantar os problemas do paciente, elaboração que as enfermeiras já realizavam, porém, de forma intuitiva e sem registros.

Para Horta ${ }^{8}$, o enfermeiro estaria capacitado a fazer o diagnóstico de enfermagem, pois detém conhecimentos das ciências básicas. Ela apresenta três justificativas para a aplicação do diagnóstico de enfermagem. Na primeira, o enfermeiro delegava os cuidados diretos do paciente ao pessoal auxiliar, necessitando de uma sistematização desta assistência. Parece não ter suscitado qualquer questionamento na categoria, inclusive sendo esse fato utilizado como justificativa para o planejamento do cuidado prestado ao paciente. Entretanto, não o era, devido ao déficit de profissionais enfermeiros, que impingia à prática assistencial a lógica da delegação de funções. Portanto, o preceito da divisão social e técnica do trabalho, encontrado no ensino e na prática assistencial, era incorporado ao processo de trabalho do enfermeiro, considerando o cuidado indireto como objeto de suas funções assistenciais.

$\mathrm{Na}$ segunda justificativa, Horta ${ }^{8}$ diz que é absolutamente antieconômico o uso de medidas empíricas, ensaios de erro e acerto; cabe ao enfermeiro o diagnóstico de enfermagem e aplicar o tratamento específico. A produtividade da área da saúde estava intimamente ligada à rotatividade dos indivíduos hospitalizados, acarretando, na enfermagem, inserida nesse mercado, a lógica da otimização do tempo ${ }^{8}$.

Finalmente a terceira justificativa aponta que 0 progresso das ciências do Homem em especial das ciências médicas exige do enfermeiro maior soma de conhecimentos, maior capacidade de reflexão, análise e síntese, levando-o, em suma, a utilizar estes processos na resolução dos problemas ${ }^{8}$.

$\mathrm{Na}$ seqüência do artigo citado, Horta propõe um plano para o tratamento de enfermagem, conhecido como plano assistencial ou de cuidados de enfermagem, focado em: cuidados higiênicos, atividades físicas, observação e controle das atividades vitais, alimentação, cuidados psicológicos, sociais e espirituais, cuidados com a medicação, ambiente e proteção contra infecções e acidentes. Um dado que chama a atenção é a preocupação da autora com o aspecto preventivo e de reabilitação, além do curativo, que deveriam nortear o plano assistencial.

Ainda em 1967, Wanda Horta et al. publicaram o artigo 0 ensino do Plano de Cuidados em Fundamentos de Enfermagem ${ }^{9}$ que trazia os resultados de suas experiências na disciplina, Fundamentos de Enfermagem, em 1963, como tarefa facultativa na escola da Universidade de São Paulo (USP), tornandose no ano seguinte, requisito básico do estágio prático, do curso de graduação. Esta iniciativa demonstrou 0 pioneirismo das enfermeiras docentes brasileiras, 0 preparo intelectual e o grau de comprometimento com a categoria, fomentando o intercâmbio internacional para fortalecimento da enfermagem brasileira.

0 ensino do plano de cuidados tinha como estrutura, roteiro de aulas teóricas compostas de: Anamnese de enfermagem, com exame físico; Diagnóstico de enfermagem; Plano de Cuidado de Enfermagem, que era subdividido em Significado e Características; Pessoas relacionadas à elaboração e execução do plano; Objetivos gerais e específicos; e Fonte de informações e elaboração do plano. A relevância da aplicação de uma sistematização já estava incorporada em 1968, por Oliveira e Rigaud ${ }^{10}$, quando apontaram o plano de cuidado integral:

Num planejamento bem feito e eficiente, por certo será este o maior testemunho de sua possibilidade de desempenhar o seu papel na equipe de saúde e de poder caracterizar-se como profissional liberal, porque terá a sua área de trabalho bem definida ${ }^{10: 462}$.

0 plano assistencial elaborado pelas enfermeiras até essa época resumia-se em anotações no Kardex ${ }^{11}$, que auxiliavam as enfermeiras na passagem de plantão e no planejamento do cuidado. Em concordância com a utilização do Kardex, a pesquisa de Oliveira e Rigaud ${ }^{10}$ realizada no Hospital da Universidade da Bahia, sobre a opinião de enfermeiras quanto à utilização deste plano de cuidado, relata as resistências a esse método, pois, embora $90 \%$ das enfermeiras pertencentes à amostra reconhecessem o seu indiscutível valor no planejamento da assistência ao paciente, elas faziam ressalvas quanto ao seu funcionamento nos moldes em que era feito.

Contudo, as idéias da sistematização da assistência baseada na metodologia científica começaram a se expandir, pois 0 artigo das autoras baianas propunha um plano escrito de assistência integral de enfermagem a pacientes hospitalizados, visando à melhoria no padrão de assistência de enfermagem ${ }^{10}$.

Contrapondo-se à falta de questionamentos quanto ao processo de trabalho da enfermagem, transparecido 
nos artigos, o editorial da REBEn de $1968^{12}$ faz enfático apelo à categoria. Ele assinala que:

Lançamos como classe um brado de alerta. Se aos auxiliares de enfermagem e aos atendentes estiverem cabendo as funções que mais importam para a cura dos internados há um grave êrro de ética profissional praticado pelos enfermeiros diplomados. Não se brinca com realidade dêste setor. A ABEn tomará providência, doa a quem doer, caso os enfermeiros não tomem, por si mesmo, o caminho apontado pelo nível de responsabilidade social que seu diploma de nivel universitário Ihes assegura ${ }^{12: 5}$.

A redação desse editorial revela a preocupação com a delimitação de funções da equipe e a busca do cuidado direto, que já suscitava questionamentos na massa crítica da Enfermagem brasileira, representada pela redatora chefe da REBEn na época, Haydeé Guanais Dourado, e pela editora, Anayde Correa de Carvalho ${ }^{12}$. Entretanto, se o trabalho manual sempre fora atribuição do pessoal auxiliar de enfermagem, desde os primórdios profissionais, por que a enfermeira tomava agora para si essas ações? Quais seriam os determinantes que direcionavam essa atitude?

Essas indagações quanto à delimitação de atividades da equipe de enfermagem não aparecem repentinamente, pois já figuravam em estudos desde o início da década de 1960, coincidindo com o aparecimento na literatura de enfermagem, da necessidade de aplicação de método científico sistematizado, delegando à enfermeira a responsabilidade do planejamento das ações prestadas ao enfermo. Porém, essa constatação traz para nós questionamentos relacionados à realidade da prática profissional da época: Como fazê-lo, se o déficit de profissionais e o fato de estarem assoberbadas de atividades administrativas dificultavam o cuidado direto? Como prestar o cuidado direto ao indivíduo, se em sua formação os 'trabalhos manuais' tinham menos valia?

Um artigo publicado em 1968, de autoria de Santos e Minzoni ${ }^{13}$, sobre as atividades de enfermagem em hospital governamental, permite clara identificação do processo de trabalho do enfermeiro, naquela época:

De nosso convivio com os problemas hospitalares sabemos de queixas constantes referentes à escassez de pessoal, a qual seria responsável por um serviço de enfermagem deficiente. A essa escassez é atribuída a necessidade das enfermeiras delegarem as pessoas de formação inferior muitas das tarefas que lhes competem. Sabemos que êste problema não é característico dêste hospital, nem da realidade brasileira e que países muito mais avançados que o Brasil tem-se defrontado com situação semelhante ${ }^{13: 396}$.

A pesquisa antes citada ${ }^{11}$ parece responder ao editorial, reconhecendo a delegação de funções. Entretanto, discorre quantitativamente sobre as atividades da equipe de enfermagem em um hospital público, fornecendo dados detalhados, tais como horário de trabalho, de cuidado direto e de cuidados organizacionais. Isto confirmava 0 discurso da categoria até então, de que quem mais lida com o paciente é $o$ atendente; segue-se $o$ auxiliar e, em seguida, a enfermeira ${ }^{1: 422}$.

Essas autoras apontam como determinantes, a escassez de enfermeiros na instituição, o salário insuficiente e o número reduzido de vagas destinadas a esse profissional evidenciando a lógica do mercado capitalista, que, para baixar os custos, contrata prioritariamente pessoal de menor qualificação, acrescentando a seus quadros profissionais graduados apenas para a administração e chefia de equipes de enfermagem. $E$ elas ainda levantam questionamentos quanto ao cuidado integral versus enfermeira administrativa. As enfermeiras estavam sendo formadas para o cuidado integral, devendo conceber o indivíduo como ser biopsicossocial, distante da prática observada na pesquisa ${ }^{11}$.

Nos anos de 1970, Horta continuou propagando a necessidade do planejamento da assistência, em três artigos datados de 1971. 0 primeiro é 0 ensino dos instrumentos básicos de enfermagem, de autoria de Horta, Hara e Paula ${ }^{14}$, no qual consideram como funções da enfermeira a determinação do diagnóstico e a elaboração e execução do plano de cuidados. Os instrumentos básicos relatados são: comunicação, planejamento, avaliação, método científico, observação, trabalho em equipe, destreza manual e criatividade. 0 segundo artigo publicado, $A$ observação sistematizada como base para o diagnóstico de enfermagem ${ }^{15}$, descreve e conceitua o histórico de enfermagem estabelecendo-o como o primeiro passo do método científico para a elaboração do diagnóstico de enfermagem.

0 terceiro artigo publicado, $A$ metodologia do processo de enfermagem ${ }^{16}$ é um marco na história da sistematização da assistência de enfermagem no Brasil. Ele coroa e agrupa a produção anterior da autora, quando conceitua e estrutura as etapas do processo de enfermagem. Nele, ela discorre sobre 0 referencial americano que embasou seus estudos, como os conceitos de 'prognóstico de enfermagem', 'histórico de enfermagem', 'plano de cuidados'. Entretanto, esclarece que haviam divergências quanto à terminologia e à metodologia utilizadas pelas enfermeiras, especialmente nos Estados Unidos. Um dado curioso, não comumente encontrado na literatura 
de enfermagem sobre Horta, é o relato encontrado neste artigo sobre um trabalho publicado que fundamentou seus estudos na metodologia científica:

Berggren e Zagornik, em artigo publicado em julho de 1968, em "Nursing Outlook", falam em "processo de enfermagem" e aí o esquematizam. Este trabalho serviu de inspiração ao nosso próprio modelo esquemático. Aí citam Ida Orlando como introdutora do termo "processo de enfermagem" porém com significado diferente do nosso ${ }^{16: 82}$.

Este trabalho de Horta ${ }^{16}$ foi a unificação de conceitos da terminologia e a estruturação completa da metodologia, citada por ela como 'processo de enfermagem'. Defende a necessidade de a enfermagem se desenvolver técnica e cientificamente e ressalta que a priorização das atividades administrativas delega o cuidado aos atendentes de enfermagem, feito de modo empírico. Se nos Estados Unidos já aparecia o elemento técnico em administração de unidade hospitalar, ela questiona: 0 que restaria ao enfermeiro? E ela responde dizendo que o enfermeiro deverá voltar às suas origens profissionais, isto é, assistir o indivíduo, família ou comunidade, no atendimento de suas necessidades básicas, mas agora utilizando-se de método próprio baseado na metodologia científica, não mais fundamentada no empirismo, no "eu acho", no atendimento somente da execução de ordens médicas, ou de cuidados rotineiros; sem perspectiva de; e que a visão da possível falta de função do enfermeiro na área da saúde, com o surgimento de novas categorias, seria o propulsor para o cuidado direto ao indivíduo.

Para tanto, Horta conceitua e define as etapas do processo de enfermagem: 1 . Histórico de enfermagem; 2. Análise dos dados, com a identificação das necessidades humanas básicas; 3. Diagnóstico de enfermagem; 4. Avaliação do diagnóstico diante das observações feitas na execução do plano terapêutico; 5. Plano terapêutico de enfermagem, englobando todos os cuidados necessários, enquanto o paciente estiver sob os cuidados do profissional; 6 . Implementação do plano e avaliação, com o plano de cuidados diário; 7. Evolução de enfermagem, anotação diária de tudo que ocorre com o paciente e 8 . Prognóstico de enfermagem.

Essa proposta foi um marco na história da metodologia da assistência de enfermagem no Brasil, corroborada por autores nesta década e na seguinte por algumas autoras (Cianciarullo, Koizumi e Fernandes ${ }^{17}$; Nogueira ${ }^{18}$; Araújo ${ }^{19}$; Resende, Andrade, e $\left.1 \mathrm{mbiriba}{ }^{20}\right)$. 0 referencial das necessidades humanas básicas, ainda hoje, fundamenta o ensino e a prática assistencial da categoria, conforme relatos de pesquisas na atualidade como: Carraro, Kletemberg, e Gonçalves ${ }^{21}$; Dell'acqua e Miyadahira ${ }^{22}$.

Com a publicação do livro de Horta ${ }^{23}$ em 1979, houve a redução de etapas do processo de enfermagem propostas em seu artigo de 1971 ( Horta $\left.^{16}\right)$, que assim ficou configurado: 1. Histórico de enfermagem; 2. Diagnóstico de enfermagem; 3. Plano assistencial; 4. Prescrição de enfermagem; 5. Evolução e 6. Prognóstico de enfermagem.

\section{DA ACEITAÇÃO À EXPANSÃO DO PROCESSO DE ENFERMAGEM}

0 diagnóstico de enfermagem deu nova dimensão às práticas do cuidado, estendendo as perspectivas profissionais ao âmbito da investigação científica, avançando para a estruturação definitiva de uma ciência da enfermagem. Esta metodologia não teve vozes discordantes publicadas na REBEn, com exceção do artigo de Amália C. Carvalho ${ }^{24}$. Discorrendo sobre 0 histórico de enfermagem, ela aponta os direitos do paciente interrogando:

Será do seu agrado submeter-se a tantos interrogatórios? Não poderá esquivar-se da anamnese do médico e, muitas vezes, de um ou muitos estudantes de medicina; terá que aceitar também que enfermeiras e estudantes de enfermagem o obriguem a tão fastidioso processo? ${ }^{24: 151}$

Esse questionamento está presente até hoje, entre os alunos de graduação quando, por vezes, consideram o histórico de enfermagem longo e exaustivo para 0 indivíduo internado.

Horta deu continuidade ao seu estudo sobre diagnóstico de enfermagem publicando o artigo Estudo básico da determinação de dependência de enfermagem, em $1972^{25}$ indicando que, para determinar o diagnóstico, a Enfermagem precisaria determinar o grau de dependência do atendimento em natureza e extensão. 0 critério de natureza divide-se em total e parcial, consistindo em ações de ajudar (A), orientar (0), supervisionar (S) e encaminhar (E).

Após a publicação sobre esta metodologia, seguiram outras publicações de relatos da aplicação do processo de enfermagem e sua validação como instrumento no processo de trabalho do enfermeiro demonstrando de maneira prática, os problemas que essa metodologia enfrentaria. Um deles identificado na aplicação da prescrição de enfermagem e relatado em 1974, por Cianciarullo, Koizumi e Fernandes ${ }^{17}$ compreendia uma $^{2}$ resistência à aplicação da metodologia científica, que já apontava nessa época: 
No entanto, quando tentamos racionalizar a assistência de enfermagem no hospital particular, encontramos barreiras, já consideradas comuns e até agora aparentemente insolúveis, tais como: enfermeiras em número insuficiente e pouco preparadas para enfrentar a realidade do hospital particular e pessoal subalterno que, mesmo sendo suficiente na quantidade, é deficitário no seu preparo. 0 planejamento de cuidados de enfermagem que nas escolas e hospitais-escola está se tornando um componente natural da enfermagem, nos demais transforma-se em "tabu" ou simplesmente é ignorado ${ }^{17: 144}$.

Esse relato expõe a restrição da aplicação da metodologia da assistência. A prática ainda não havia incorporado a sistematização da assistência em seu processo de trabalho. Essa resistência à aplicação da metodologia científica ainda hoje é percebida nas instituições brasileiras.

A deficiência quantitativa no número de enfermeiras, principalmente em hospitais não-governamentais é testemunhada pelas enfermeiras responsáveis pela avaliação do serviço no INPS, em artigo publicado em 1976 (Oguisso e Schmidt ${ }^{26}$ ). Essas autoras fazem um relatório da assistência hospitalar dos enfermeiros destacando:

A não ser em Unidades de Terapia Intensiva e em alguns poucos hospitais governamentais que contam em seu quadro de pessoal com enfermeiras em número até razoável, a grande maioria ou a quase totalidade dos hospitais não governamentais não dispõe, ainda, de enfermeiras para dar cobertura assistencial direta ${ }^{26: 25}$.

Dessa forma, a tônica da produtividade a baixo custo ainda era forte, pois as enfermeiras concentravam-se nos hospitais públicos, dada a escassez de oportunidades na iniciativa privada. As enfermeiras ficavam em cargos diretivos do serviço de enfermagem do hospital, ou em chefia de centro cirúrgico ou obstétrico, ou ainda na supervisão de grandes áreas, às vezes, isso extrapolava o próprio serviço de enfermagem e elas responsabilizavam-se por setores outros, como nutrição e lavanderia.

Essas atividades administrativas distanciavam a enfermeira do cuidado direto, acarretando nela receio de desempenhar esse papel, quando solicitado:

[...] Algumas enfermeiras quando entrevistadas, após vistoria, confessavam simplesmente não ter segurança para executar esta ou aquela técnica. Entre estas técnicas destacamos a sondagem gástrica, vesical, enteroclisma, certos curativos e até aplicação de venóclise. Conseqüência direta desta insegurança será, por certo, a fuga destas situações, em detrimento da supervisão e orientação de funcionários, função específica das enfermeiras nesses hospitais ${ }^{26: 23}$.

Essa confissão revela a dicotomia entre a teoria e a prática assistencial. Enquanto aquela pregava 0 retorno ao cuidado integral, essa mostrava as deficiências e inseguranças dos profissionais em prestar a assistência direta. Assim, a enfermeira que prestaria o cuidado direto ao paciente deveria também se ocupar das tarefas administrativas, o que retirava sua destreza na execução da técnica, expondo-a a avaliação por parte do pessoal auxiliar. Isso evidencia a inadequação do ensino à prática das enfermeiras, um descompasso entre o fazer e o saber.

A preocupação na década de 1970 consiste, portanto, na eficácia da competência técnica como meta a ser perseguida por todos os profissionais de enfermagem, com vistas a contribuir com 0 avanço tecnológico, com o desenvolvimento, numa preparação parcial, voltada exclusivamente para 0 atendimento hospitalar, e ao mercado de trabalho. Por sua vez 0 reflexo na educação foi a criação dos primeiros cursos de pós-graduação voltados preferencialmente para as áreas médica e cirúrgica, que ofereciam maior número de vagas no mercado de trabalho.

Concomitantemente a isso, a publicação de artigos sobre a metodologia da assistência prosseguia. Em artigo publicado em 1976 por Paim² ${ }^{27}$, ela ressaltava a importância da prescrição de enfermagem como uma [...] atividade principal do enfermeiro e, portanto, corresponde àquela unidade de trabalho que, uma vez assumida, projetará toda nossa autonomia de enfermeiros no desempenho profissiona ${ }^{\text {77:67. Ela }}$ destacou que, embora desde 1965 o Congresso Brasileiro de Enfermagem recomendasse a utilização de planos de cuidados de enfermagem, isso não foi assumido pelos profissionais como prioritário no desempenho de suas ações. Fazendo alusão futurista, a autora discorre ainda sobre a possibilidade de programar as prescrições em computadores e unificada com outros profissionais de saúde, que, nos dias atuais, ainda é uma aspiração.

Os registros de enfermagem foram também tema de estudo de Duarte, Reis e Santos ${ }^{28}$, em 1976. Em sua pesquisa, elas verificaram que havia defasagem entre o que era preconizado no dimensionamento da enfermagem e o que era encontrado no exercício da profissão, apontando que os serviços de enfermagem deveriam desenvolver programas de atualização e treinamento do grupo. 
Apesar das dificuldades de implementação apontadas, pesquisas como a de Luckesi et a ${ }^{29}$ relatam mais uma vez a relevância profissional dessa sistematização na fala dos enfermeiros destacando que assim, no geral, as enfermeiras sentem que o processo de enfermagem [...] dá um cunho científico e eficiente à sua ação; proporciona maior autonomia profissional; facilita a assistência específica ao paciente ${ }^{29: 151}$. Neste sentido, houve uma valorização da temática considerando-se que além de Horta, outras autoras propuseram uma metodologia para sistematizar as ações de enfermagem, como Lygia Paim, Rosalda Paim e Liliana Daniel, tal como referido por Paula et a ${ }^{\beta 0}$.

A falta de utilização da sistematização da assistência também é relatada por Caldas, Pereira e Alvarez $^{31}$, em artigo de 1976. Essas autoras demonstram que esses instrumentos não estavam padronizados nem visavam à racionalização do trabalho, e restringiam-se a folha única de anotações, balanço hídrico e gráfico de sinais vitais.

Há, entretanto, relatos de registros sistematizados, como escrevem Maria et $a{ }^{11}$, de uma experiência de cinco anos de utilização da ficha Kardex. Essa iniciativa demonstra que a teoria da metodologia da assistência foi validada na prática assistencial, pois as autoras relatam a experiência das anotações de forma sistematizada, para facilitar seu processo de trabalho. É curiosa a revelação das autoras de que as anotações eram primeiramente escritas a lápis e, posteriormente, a tinta, por incentivo da médica que compunha a equipe, pois não faziam parte do prontuário do paciente. Os registros eram compostos por: ficha de entrevista (identificação, condições gerais, queixas e observações do enfermeiro); a ficha de recomendações (em que eram anotadas as ocorrências durante a internação); e a ficha de internação (preenchida na admissão e enviada à unidade de internação).

No entanto, percebe-se que o desenvolvimento dos registros sistematizados visavam à solução de problemas administrativos e não a favorecer 0 planejamento da assistência, tendo a enfermeira de buscar melhoria na qualidade do serviço prestado.

0 ensino do processo de enfermagem está relatado no artigo de Koch e Oka $^{32}$ (1977), no qual evidenciam que a maioria dos discentes não acreditava em sua aplicabilidade prática, devido principalmente à sua complexidade, que exigia muito tempo para execução. Esse artigo talvez forneça subsídios para compreender como 0 aluno da graduação modificava a prática assistencial, ao levar o aprendizado da academia para a prática. Se esse aluno, ao se graduar, não se motivava com o processo de enfermagem, como implementá-lo em seu processo de trabalho? Some-se como agravante, a não aplicação desta metodologia em seus campos de estágio.

Outro relato das resistências é fornecido por artigo que discorre sobre a implantação do processo de enfermagem no Hospital Anna Nery. As autoras referem que as:

Dificuldades foram encontradas na implantação do Processo de Enfermagem no Hospital Ana Nery e continuam a estar presentes em sua execução. Em primeiro lugar por ser uma metodologia nova de trabalho e, em segundo, porque em toda e qualquer mudança metodológica ocorrem resistências ${ }^{29: 151 .}$

$\mathrm{Na}$ análise dos artigos da Revista Brasileira de Enfermagem, observou-se pluralidade de termos utilizados com o mesmo significado, como: planejamento de cuidados, plano assistencial e plano de cuidados; anotações e registros; sistematização da assistência, processo de enfermagem e metodologia da assistência.

Essa diversidade pode ter contribuído para dificultar a socialização do conhecimento, especialmente num país de dimensões continentais como o Brasil. Assim, a pluralidade de nomenclaturas para designar a metodologia da assistência também contribuiu para que profissionais não se apropriassem desse método científico em seu processo de trabalho.

Chama à atenção na análise documental a quase unanimidade da autoria dos artigos, que é de docentes que relatam experiências em hospitais-escola, os quais, apesar de reconhecerem o processo de enfermagem, apontam as dificuldades de sua aplicação. Assim, apesar dos profissionais reconhecerem a relevância da metodologia da assistência para sua prática laboral, sua utilização e pesquisas relativas ao tema estão restritas à academia e aos hospitais-escola, palco das aulas práticas da graduação.

0 enfermeiro assistencial tinha resistência à aplicação dessa sistematização principalmente, pelo desconhecimento desta nova metodologia, fato que foi relativizado a partir da criação dos cursos de pósgraduação na década de 1970, que permitiram a maior socialização do saber em enfermagem.

Os anos 1980 inauguram nova proposta de trabalho para o Sistema de Serviços de Saúde, baseada na AlmaAta, com os Cuidados Primários de Saúde. 0 foco do cuidado que outrora fora predominantemente curativa foi contestado, iniciando-se o movimento de prevenção e extensão da cobertura de cuidados de saúde à população.

A implementação da metodologia da assistência de enfermagem prosseguiu, nessa década, com a publicação de artigos de relato de experiências de enfermeiras na aplicação do processo de enfermagem, com adequações. Algumas relatam a aplicação de forma 
mais sucinta. A percepção na análise é de que algumas etapas vão sendo excluídas, como plano de cuidados e prognóstico de enfermagem, com base principalmente na viabilidade prática do processo.

Outra característica é a diversificação das Teorias de Enfermagem que fornecem o embasamento teórico para a prática assistencial, como a publicação sobre a aplicação da teoria de Myra Levine, no processo de enfermagem na saúde comunitária ${ }^{33}$. Some-se a isso a necessidade de adaptação multidisciplinar, com 0 surgimento de novas profissões na área da saúde.

\section{CONCLUSÃO}

0 desenvolvimento da metodologia da assistência de enfermagem esteve contextualizado nos caminhos percorridos para a profissionalização da enfermagem no Brasil, que foi fundada sob interesses do governo, mercado de trabalho e do ensino de enfermagem.

Esses interesses refletem-se nas políticas de saúde, que, nas décadas de 1960 e 1970, privilegiavam a prática curativa, individual e especializada e a assistência previdenciária, acarretando a lógica da expansão na área hospitalar, direcionando o mercado de trabalho e o ensino da enfermagem. Foi nesse período de expansão hospitalar, da ênfase nas práticas curativas, da procura pela valorização profissional, que se inseriu 0 planejamento da assistência, buscando o embasamento científico no processo de trabalho do enfermeiro.

As décadas de 1970 e 1980 caracterizaram-se pela validação desse instrumento pela categoria e por os

\section{Referências}

1. Carraro TE. Da metodologia da assistência de Enfermagem: sua elaboração e implementação na prática. In: Carraro TE, Westphalen, ME. A. Metodologias para a assistência de Enfermagem: teorizações, modelos e subsídios para a prática. Goiânia(G0): AB Editora; 2001.

2. Meier, MJ. Técnica e tecnologia mediando o saber-fazer na Enfermagem. (Dissertação de Mestrado). Curitiba(PR): Centro Federal de Educação Tecnológica do Paraná/ CEFET);1998

3. Mendes, MA, Bastos, MAR. Processo de Enfermagem: seqüências no cuidar fazem a diferença. Revista Brasileira de Enfermagem 2003 mai./jun; 56(3): 271-276

4. Thofehrn, MB et al. 0 processo de enfermagem no cotidiano de acadêmicos de Enfermagem e enfermeiros. Revista Gaúcha de Enfermagem 1999 jan; 20(1): 69-79.

5. Congresso Nacional (BR). Lei $n^{\circ} 7.498$, de 25 de junho de 1986. Regulamentação do exercício da enfermagem e dá outras providências. Diário Oficial da República Federativa do Brasil. Brasília(DF), 30 jun 1986.

6. Benjamin, W. Magia e técnica, arte e política. São Paulo(SP): Brasiliense; 1986.

7. Germano, RM. Educação e ideologia da Enfermagem no Brasil. São Paulo(SP): Cortez; 1983. esforços culminarem com a Lei 7.498 , de 25 de junho de 1986, que regulamentou a prescrição de enfermagem e a consulta de enfermagem como responsabilidade do enfermeiro.

No período estudado, o universo de trabalho da enfermagem modificou-se. A enfermeira teve que atuar eficazmente, diante de exigências antagônicas: o mercado que exigia maior complexidade de conhecimentos e especificidades do cuidado, para acompanhar o avanço tecnológico na área médica; 0 cuidado direto e o planejamento da assistência não interessavam às instituições, e, sim, o bom andamento do serviço de enfermagem; a academia, conclamando para o cuidado direto ao paciente e o planejamento das ações da equipe de enfermagem; o déficit de profissionais, acarretando número expressivo de enfermos sob seus cuidados; as atividades administrativas cobradas pelas instituições empregadoras; a falta de destreza na execução de algumas técnicas, que a colocavam sob avaliação da equipe quanto a sua competência; a dificuldade do cumprimento das ações prescritas pelo enfermeiro, devido ao despreparo dos atendentes de enfermagem, representantes majoritários da força de trabalho no período.

A implantação da metodologia da assistência de enfermagem está inserida nesse contexto. Portanto, as dificuldades e resistências experimentadas não podem ser contabilizadas apenas à vontade dos profissionais, mas, sim, permearam-se pelos interesses antagônicos da sociedade brasileira.

8. Horta, WA. Considerações sobre o diagnóstico de enfermagem. Revista Brasileira de Enfermagem 1967 jan/fev; 20(1): 7-13.

9. Horta, WA. O ensino do Plano de Cuidados em Fundamentos de Enfermagem. Revista Brasileira de Enfermagem 1967 ago; 20(4): 249-263.

10. Oliveira, C.; Rigaud, HM. Plano de cuidado integral de enfermagem ao paciente hospitalizado. Revista Brasileira de Enfermagem 1968 out; 21(5): 458-470.

11. Maria, VLR, Iwakura, KH, Lim, TA, Medeiros, SL. Evolução do paciente: anotações de enfermagem no Kardex e passagem de plantão com equipe multiprofissional. Revista Brasileira de Enfermagem 1977 jul/set; 30(3): 237-243.

12. Editorial. Funções de enfermeiros. Revista Brasileira de Enfermagem 1968 jan/jun; 21(1).

13. Santos, CF, Minzoni, MA. Estudo das atividades de enfermagem em quatro unidades de um hospital governamental. Revista Brasileira de Enfermagem 1968 out; 21(5): 396-442.

14. Horta, WA, Hara, Y, Paula, NS. 0 ensino dos instrumentos básicos de enfermagem. RevistaBrasileira de Enfermagem 1971 abr/jun; 24(3): 159-169.

15. Horta, WA Observação sistematizada como base para 0 diagnóstico de enfermagem. Revista Brasileira de Enfermagem 1971 jul/set; 24(5): 46-52. 
16. Horta, WA. A metodologia do processo de enfermagem. Revista Brasileira de Enfermagem 1971 out/dez; 25(6): 81-95.

17. Cianciarullo, TI, Koizumi, MS, Fernandes, RAQ. Prescrição de enfermagem: Experiências de sua aplicação em hospital particular. Revista Brasileira de Enfermagem 1974 abr/jun; 27(2): 144-149.

18. Nogueira, MJC. Uma experiência com consultas de enfermagem para crianças. Revista Brasileira de Enfermagem 1977 jul/set; 30(3): 294-306.

19. Araújo, OMM. Consulta de enfermagem a gestante. Revista Brasileira de Enfermagem, Brasília 1979 jul/set; 32(3): 259-270.

20. Resende, LB, Andrade, VRO, Imbiriba, CE. Implantação da metodologia assistencial no IASERJ. Revista Brasileira de Enfermagem $1981 \mathrm{abr} / j u n ; 34(2): 123-137$.

21. Carraro, TE, Kletemberg, DF, Gonçalves, LM. 0 ensino da metodologia da assistência de Enfermagem no Paraná. Revista Brasileira de Enfermagem 2003 set/out; 56(5): 499-501.

22. Dell'acqua, MCQ, Miyadahira, AMK. Ensino do processo de Enfermagem nas escolas de graduação em Enfermagem do Estado de São Paulo. Revista latino-americana de Enfermagem 2002 mar/ abr; 10(2):.185-191.

23. Horta, WA. Processo de Enfermagem. São Paulo(SP): EPU; 1979.

24. Carvalho, A. C. Considerações sobre o ensino de campo na enfermagem. Revista Brasileira de Enfermagem 1972 out/dez; 25(5):149-153.

25. Horta, WA. Estudo básico da determinação de dependência de enfermagem. Revista Brasileira de Enfermagem 1972 jul/set; 25(4):267-273.

26. Oguisso, T, Schmidt, MJ. Problemas assistenciais de enfermagem nos hospitais e clínicas particulares. Revista Brasileira de Enfermagem 1976 fev; 29(1):24-37.

27. Paim, L. Sistema de registros de enfermagem, plano assistencial e prescrições de enfermagem. Revista Brasileira de Enfermagem $1976 \mathrm{jul} / \mathrm{set} ; 29(3): .66-82$.

28. Duarte, AB, Reis, IEM, Santos, VO. Importância das anotações dos cuidados de enfermagem. Revista Brasileira de Enfermagem $1976 \mathrm{jul} / \mathrm{set} ; 29(3):$ 83-91.

29. Luckesi, MAV, Amorim, MJAB, Silva, NF, Nunes RS. Aplicação do processo de enfermagem no Hospital Ana Nery. Revista Brasileira de Enfermagem 1978 abr/jun; 31(2): 141-156.
30. Paula, NS, Farias GM, Araújo TL, Takahashi, OC. Assistência de Enfermagem sistematizada - experiência de aprendizado. Revista Brasileira de Enfermagem 1984 jan/mar; 37(1): 65-71.

31. Caldas, NP, Pereira, AC, Alvarez, L. H. Instrumentos de registro das atividades de enfermagem. Revista Brasileira de Enfermagem $1976 \mathrm{jul} / \mathrm{set}$; 29(3): 92-102.

32. Koch, RM, Oka, LN. Processo de enfermagem - avaliação feita por alunos do Departamento de Enfermagem da UCP. Revista Brasileira de Enfermagem 1977 jul/set; 30(3): 274-285.

33. Fagundes, NC. 0 processo de enfermagem em saúde comunitária a partir de Myra Levine. Revista Brasileira de Enfermagem 1983 jul/ dez; 36(3): 265-273.

\section{Nota}

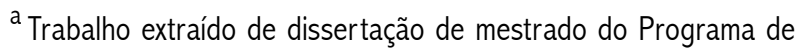
Pós-graduação em Enfermagem, Setor de Ciências da Saúde da Universidade Federal do Paraná.

\section{Sobre as Autoras}

\section{Denise Faucz Kletemberg}

Enfermeira. Mestre em Enfermagem. Professora Assistente da Faculdade Evangélica do Paraná - Curitiba. Membro do Grupo de Estudos Multiprofissional em Saúde do Adulto - GEMSA.

\section{Márcia Dalledone Siqueira}

Historiadora. Doutora em História. Professora do Departamento de História da Universidade Federal do Paraná - Orientadora

\section{Maria de Fátima Mantovani}

Enfermeira. Doutora. ProfessoraAdjunta do Departamento de Enfermagem da Universidade Federal do Paraná. Coordenadora do Grupo de Estudos Multiprofissional em Saúde do Adulto - GEMSA- Co- orientadora 